\title{
Behavioral and Neuroendocrine Effects of the Partial NMDA Agonist D-cycloserine in Healthy Subjects
}

\author{
B. N. M. van Berckel, M.D., C. Lipsch, S. Timp, C. Gispen-de Wied, M.D., Ph.D., H. Wynne, Ph.D., \\ J. M. van Ree, Ph.D., and R. S. Kahn, M.D., Ph.D.
}

The effects of $D$-cycloserine, a partial agonist of the $N$-Methyl-D-Aspartate (NMDA) receptor, were assessed in a (neuroendocrine) challenge paradigm to examine NMDA systems in male healthy volunteers, using a double-blind, placebo-controlled crossover design. Oral D-cycloserine $(15,50$, and $150 \mathrm{mg})$ was readily absorbed and its plasma concentration increased dose-dependently. Behavioral and hormonal responses were measured for 240 minutes after administration of the drug. $D$-cycloserine was well tolerated and did not induce side-effects according to the Visual Analog Scales (VAS), the Brief Psychiatric Rating Scale
(BPRS) and the Adverse Events Checklist (AEC) \& codes. $D$-cycloserine failed to elicit a neuroendocrine response as evaluated by cortisol, prolactin, and luteinizing hormone (LH) plasma levels. The present result suggests that $D$-cycloserine can readily be administered to healthy volunteers but that, in the dosages used, neuroendocrine secretion fails to serve as a model for testing NMDA receptor function in humans. [Neuropsychopharmacology 16, 317-324] (C) 1997 American College of Neuropsychopharmacology
KEY WORDS: D-cycloserine; NMDA; schizophrenia; LH; cortisol

In schizophrenia research, interest in the role of glutamate, one of the excitatory amino acids, is increasing (Henn 1995; Olney and Farber 1995). A possible role for excitory amino acids and their receptors in the pathophysiology of schizophrenia was suggested after the observation that antagonists to one of the receptors of glutamate, the N-Methyl-D-Aspartate (NMDA) receptor, like phencyclidine (PCP) and ketamine, were able to induce schizophrenia-like symptoms in healthy subjects and to cause exacerbation of schizophrenic

From the Department of Psychiatry, University Hospital Utrecht, and the Rudolf Magnus Institute for Neurosciences and the Centre for Biostatistics, University of Utrecht (HW).

Address correspondence to: Bart N. M. van Berckel, M.D., Department of Psychiatry, University Hospital Utrecht, P.O. Box 85500, 3508 G.A., Utrecht, the Netherlands.

Received March 15, 1996; revised August 23, 1996; accepted August 23, 1996. symptoms in patients with schizophrenia (Luby et al. 1962, for review see Javitt and Zukin 1991; Krystal et al. 1994; Lahti et al. 1995). These observations suggest that a hypofunction of the glutamaterigic system might play a role in the pathophysiology of schizophrenia. This hypothesis is supported by postmortem studies: an increase in glutamatergic receptors in the prefrontal (Nishikawa et al. 1983; Toru et al. 1988), parietal, and occipital cortex (Ishimaru et al. 1994) of the brain of patients with schizophrenia was found. This increase in glutamatergic receptors has been explained as a compensatory mechanism for decreased function of glutamatergic neurons. Indeed, by measuring presynaptic markers of glutamatergic neurons ( $\mathrm{N}$-acetylaspartylglutamate and $\mathrm{N}$-acetyl- $\alpha$-linked acidic dipeptidase), a hypofunction of glutamatergic neurotransmission in the prefrontal cortex and hippocampus in schizophrenic patients has recently been supported (Tsai et al. 1995). Finally, diminished function of glutamatergic neurons in schizophrenia is suggested by the observation that treatment of patients 
with agonists of the glycine recognition site of the NMDA receptor, like D-cycloserine and glycine, ameliorated some (mainly negative) symptoms of schizophrenia (Javitt et al. 1994; Goff et al. 1995; van Berckel et al. 1996). Limited in vivo information is available about the glutamatergic system and NMDA receptor function in patients with schizophrenia. As in animals glutamate is one of the major regulatory neurotransmitters in the secretion of pituitary hormones, acting mainly through non-NMDA (van den Pol et al. 1990), but also through NMDA, receptors (Carbone et al. 1996), neuroendocrine secretion in response to NMDA receptor ligands may serve as a probe to test NMDA receptor function. This neuroendocrine challenge paradigm has already been used to examine serotonin (5-HT; Kahn and Wetzler 1991) and noradrenalin (NA; Glazer et al. 1987) systems in healthy subjects and various patient groups, including schizophrenic patients. That this approach may be useful in examining the NMDA system as well is suggested by animal studies, as NMDA receptors appear to be involved in regulating secretion of luteinizing hormone (LH) (Schainker and Cicero 1980; Arslan et al. 1988; Petersen et al. 1991), ACTH (Jezova et al. 1991) and prolactin (for review see Arslan et al. 1992). So far, only one human study has addressed this issue, examining the effects of the non-competitive NMDA antagonist ketamine on cortisol and prolactin secretion in healthy subjects and reporting a dose-related increase in both cortisol and prolactin plasma levels (Krystal et al. 1994). However, ketamine also induced behavioral changes: ketamine was in the dose that stimulated cortisol and prolactin secretion in general anxiogenic. Therefore, it cannot be exluded that these hormonal effects are secondary to the behavioral effects.

D-cycloserine, an antibiotic used in the treatment of tuberculosis (Rivas Salazar 1970), is a partial agonist of the NMDA receptor (Thompson et al. 1992) and crosses the blood-brain barrier (Hanngren et al. 1961). Comparing neuroendocrine responses induced by D-cycloserine between schizophrenic patients and normal controls could serve to test human NMDA receptor function in these groups. D-cycloserine dosage and blood level are critical variables in this challenge paradigm, because they determine D-cycloserine availability at the NMDA receptor site. Thus, this study examined the behavioral and neuroendocrine effects of D-cycloserine in healthy subjects. Selection of dosage was based on prior studies in humans, indicating that 15,50 , and $100 \mathrm{mg}$ doses of D-cycloserine were well tolerated in human subjects (Jones et al. 1991; Goff et al. 1995; van Berckel et al. 1996).

\section{MATERIALS AND METHODS}

\section{Subjects}

Sixteen healthy male volunteers were recruited through university newspaper advertisements. Only physical healthy subjects without a personal or family history in first-degree relatives of psychiatric illness could participate. All responders to the advertisement were first interviewed by telephone and, if suitable, were invited to the University Hospital Utrecht to complete the screening procedure. All potential research subjects underwent physical and psychiatric examination, using the Comprehensive Assessment of Symptoms and History (CASH; Andreasen 1985) and the Structured Interview for DSM-III-R Personality Disorder-Revised Dutch version (van den Brink and de Jong 1992). Subjects all had an electrocardiogram and routine laboratory tests, including complete blood count, thyroid function tests, urine analysis, and urine toxicology screen for drugs of abuse. All subjects had a body mass index (BMI) between 20 and 25, were between 18 and 31 years, and had an average level of physical exercise. The study was approved by the Human Ethics Board of the University Hospital Utrecht. After written and oral information had been given, written informed consent was obtained from all subjects before enrollment in the study.

\section{Experimental Design}

In a randomized, double-blind, Latin-square design, 16 men with a mean age of 24 years $(\mathrm{SD}, 3.3$ years; range, 18 to 31 years; weight, $76.5 \pm 7.9 \mathrm{~kg}$; height, $183 \pm 0.8$ $\mathrm{cm}$; BMI, $22.6 \pm 1.9$ ) each received 3 oral doses of D-cycloserine (15, 50 and $150 \mathrm{mg}$ ) and one of placebo on four separate occasions, a minimum of 1 week apart, between April and August 1995. The 16 subjects were randomly allocated to 4 Latin Squares, chosen in such a way that all dosages were given 4 times on the first, second, third, and fourth test day. Furthermore, none of the subjects received the same sequence of dosages. Neuroendocrine, D-cycloserine plasma levels, physiological, and behavioral measure were collected over a 4.5-hour period during each session.

\section{Procedure}

Subjects arrived at the Metabolic Ward of the Department of Psychiatry, University Hospital Utrecht at 8:30 A.M., having fasted since 11:00 P.M. the preceding day. They reclined on a bed until 1:00 P.M. They were not allowed to eat, sleep, smoke, or watch television until the procedure was completed. Between 8:30 and 8:45 A.M., one indwelling intravenous catheter was inserted into the antecubital vein and kept opened with $1 \mathrm{ml}$ heparin $(100 \mathrm{U} / \mathrm{ml})$, infused after each blood sample and removed before the following blood sample. After inserting of the intravenous catheter, baseline blood samples were obtained following a 45-minute rest period at 9:30 A.M. and again 30 minutes later at 10:00 A.M. to determine baseline hormone concentrations. Immediately following the collection of the last baseline sample at 
10:00 A.M., subjects received an oral dose of D-cycloserine or placebo. Additional blood sample were collected $30,60,90,120,150,180$, and 240 minutes after the oral dose. In addition, at these time points, sublingual body temperature, blood pressure, and heart rate were assessed. Furthermore, at 0, 60, 120, 180, and $240 \mathrm{~min}-$ utes behavioral measurements were performed. Blood samples were collected in 10-cc plastic tubes containing EDTA. They were centrifugated (10 minutes at 3,000 rounds $/$ minutes at $4^{\circ} \mathrm{C}$ ) within 5 minutes of sampling. Plasma was allocated into plastic tubes and stored at $-80^{\circ} \mathrm{C}$ until the time of the assays.

\section{Neuroendocrine, D-cycloserine Plasma Levels, Behavioral, and Physiological Measurements}

Assessment of D-cycloserine Plasma Levels. D-cycloserine plasma levels were determined using a fully automatic high-performance liquid chromatographic (HPLC) analysis with fluorescence detection. In the D-cycloserine assay, a fully automated precolumn derivatization was performed. The HPLC system consisted of a PharmaciaLKB pumpmodel 2249 (Pharmacia, Woerden, the Netherlands) equipped with a low-pressure mixing module, a Gilson 231 XL auto-sampler (Meyvis, Bergen op Zoom, the Netherlands) supplied with a Rheodyne injection valve 7010 and a $20-\mu 1$ loop. Detection was performed with an Applied Biosystems fluorometer model 980 (Exetation $230 \mathrm{Nm}$, Emission $>470 \mathrm{Nm}$, Seperation B.V., Waddinxsveen, the Netherlands) connected to a dataintegrating system. Analyses were performed on a 5- $\mu \mathrm{m}$ Supelcosil 8-DB $25 \mathrm{~cm} \times 4.6 \mathrm{~mm}$ (Id) column from Supelchem (Leusden, the Netherlands). The detection limit of the assay was $2 \mu \mathrm{M}$.

Neuroendocrine Measurements. At the end of all tests of one subject, all measurements were carried out in one assay to avoid interassay variation by a technician blind to the order and nature of drug sequence. Prolactin was measured by the Enzymun-Test Prolactin, a noncompetitive enzyme immunometric assay (IEMA, Boehringer Mannheim Immuno-diagnostics, Germany). The prolactin standard has been calibrated against the WHO-standard 84/500 (3rd IRP). The interassay variation was between $3.1 \%$ and $7.1 \%$, the detection limit was $0.03 \mathrm{U} / 1$. LH was measured by the Enzymun-Test (Boehringer Mannheim Immuno-diagnostics, Germany) also an IEMA. The LH standard has been calibrated against the NIBSC standard 2nd ISP 80/552. Interassay variation was between $2.4 \%$ and $6.7 \%$, detection limit was $0.2 \mathrm{U} / 1$. Prolactin and LH assays are automated on the ES600. Cortisol was measured using a competitive fluorescence polarization immunoassay (FPIA, Abbott Laboratories, ILL, USA). Calibrators are referenced against Abbott Reference Standards. Interassay variation was between $3.8 \%$ and $4.6 \%$, and detection limit was $0.01 \mu \mathrm{mol} / 1$.
Assessment of Temperature and Cardiovascular Responses. Sublingual body temperature was assessed with a digital thermometer. Blood pressure and pulse were measured with an Omega 1400 noninvasive, fully automatic blood pressure method.

Assessment of Mood and Other Psychological Responses. Three rating scales were used to assess psychological and somatic changes associated with D-cycloserine administration: The Brief Psychiatric Rating Scale (BPRS; Overall and Gorham 1962), the Adverse Event Checklist and Visual Analog Scales (VAS; Bond and Lader 1974). From the VAS afterward three factors were calculated: alertness, contentedness, and calmness.

\section{Drugs}

D-cycloserine was provided by Eli Lilly in capsules of $250 \mathrm{mg}$. Capsules of 5, 50, and $150 \mathrm{mg}$ D-cycloserine and placebo were prepared in identical capsules by the pharmacy department of the University Hospital Utrecht. According to good laboratory practice, a sample of these capsules was analyzed in the Laboratory of Biological Psychiatry, University Hospital Utrecht, by a technician blind to content of the capsules.

\section{Statistical Analysis}

Biochemical, neuroendocrine, and behavioral effects and vital signs were analyzed by means of multivariate analysis of variance (MANOVA) with repeated measures on the within-subjects factors time and dosage. Time, dosage, and time-by-dosage effects were evaluated. The latter, being of special interest, was examined post hoc for contrasts among dosages. In addition, areas under the concentration-time curve (AUC) for the biochemical and neuroendocrine variables, as well as the maximum change from baseline for vital signs, biochemical, and neuroendocrine measurements, were analyzed by analysis of variance (ANOVA) with repeated measures on dosage. Polynomial contrasts were used to detect possible dose-response relationships. Analysis of covariance (ANOVA) was used to correct for subjectrelated variables, such as BMI.

\section{RESULTS}

\section{D-cycloserine Plasma Levels}

The different $\mathrm{D}$-cycloserine dosages produced a dosedependent rise in D-cycloserine plasma levels (Figure 1). Multivariate analysis for AUC data revealed a significant dose effect (Wilks's $F_{2,14}=48.37, p<.001$ ). Paired $t$-tests revealed a significant rise in AUC of the $50-\mathrm{mg}$ dose $(t=-7.56, \mathrm{df}=15, p<.001)$ and the $150-\mathrm{mg}$ dose $(t=-9.87, \mathrm{df}=15, p<.001)$ compared to the 15-mg dose. The 150-mg D-cycloserine produced a signifi- 


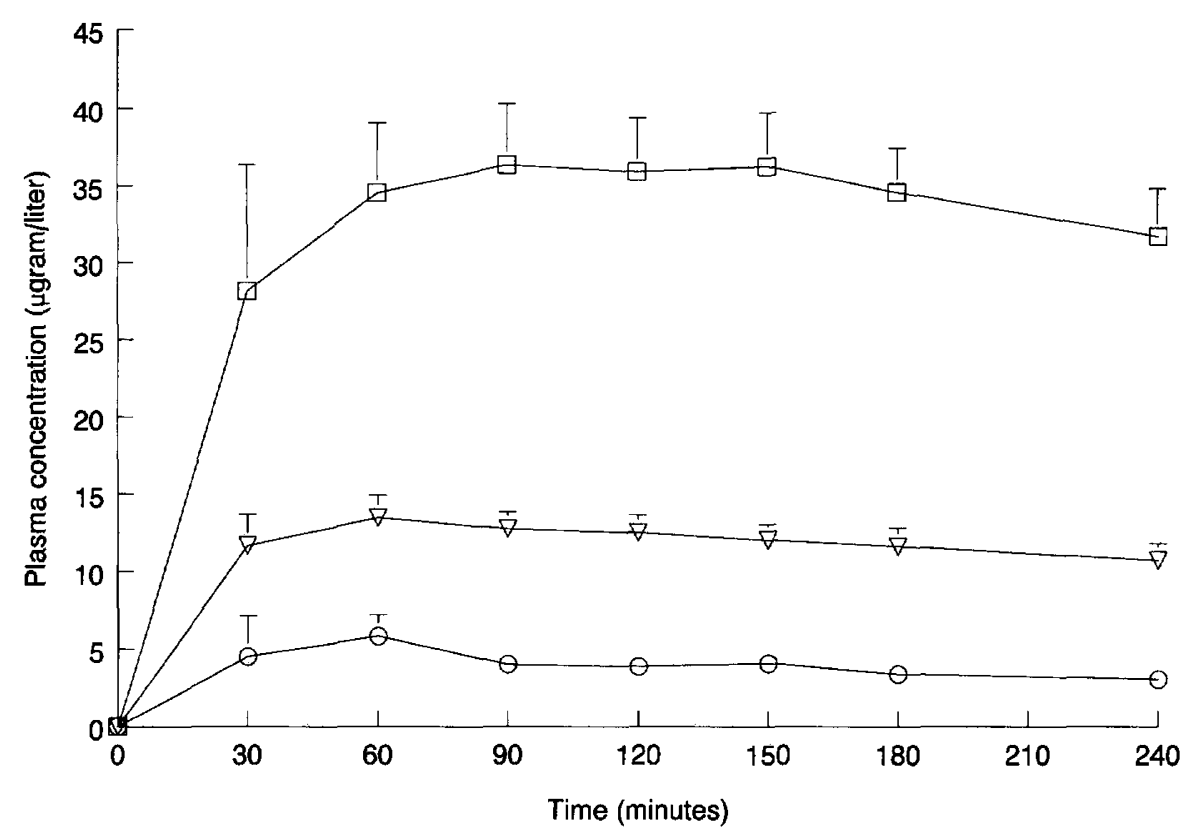

Figure 1. D-cycloserine plasma concentrations after oral administration of $15 \mathrm{mg}$ (circles), $50 \mathrm{mg}$ (triangles), and $150 \mathrm{mg}$ (squares) D-cycloserine. cantly higher AUC $(t=-8.44, \mathrm{df}=15, p<.001)$ than the 50-mg dose.

\section{Neuroendocrine Measurements}

LH. D-cycloserine did not induce a change in $\mathrm{LH}$ plasma levels (Figure 2A). Multivariate analysis for plasma levels revealed no time or dose effect nor an interaction (dose $\times$ time). An ANOVA of AUC data with repeated measures on dosage revealed no effect of D-cycloserine $(F=0.47, \mathrm{df}=2, p=.628)$.

Cortisol. D-cycloserine did not induce a change in cortisol plasma levels (Figure 2B). Multivariate analysis revealed a significant time effect (Wilks's $F_{7,9}=5.97$, $p=.008$ ), but no effect for dose or interaction (dose $\times$ time). A repeated-measures ANOVA on dose for AUC data revealed no effect of $\mathrm{D}$-cycloserine $(F=.22$, $\mathrm{df}=2$; $p=.80$ ).

Prolactin. None of the D-cycloserine dosages produced a change in circulating prolactin (Figure 2C). Multivariate analysis revealed a significant time effect (Wilks's $F_{7,9}=8.26, p=.003$ ), but no effect for dose or interaction (dose $\times$ time). A repeated-measures ANOVA on dose for AUC data revealed no effect of D-cycloserine $(F=0.27, \mathrm{df}=2, p=.76)$.

\section{Body Temperature, Blood Pressure, and Heart Rate}

There was no significant effect of D-cycloserine at any dosage level or placebo on blood pressure, heart rate, or temperature.

\section{Psychological Effects}

Mood States. No effects of D-cycloserine administration were noticed on the sum scores of the times contributing to factor alertness, contentedness, and calmness.

BPRS. No effects of D-cycloserine were noticed on any of the BPRS items and clusters.

Side Effects. Adverse Events Listings report mild headache in six subjects, one during the placebo test, two after 15-mg D-cycloserine, one after 50-mg, and two after the 150-mg D-cycloserine dose. One subject reported blurred vision after receiving the 15-mg D-cycloserine dose, and one other subject complained of nausea after placebo administration. No relation between D-cycloserine administration and these reported effects is suspected. In general, D-cycloserine was well tolerated.

\section{DISCUSSION}

The main findings of this study are that 15,50 and 150 mg D-cycloserine administered orally were readily absorbed and that the drug's plasma concentration increased dose-dependently in male healthy volunteers; that D-cycloserine was well tolerated and did not induce side effects; and that D-cycloserine failed to elicit a cortisol, LH, or prolactin response. These results are compatible with absorption characteristics and tolerance of D-cycloserine (Goff et al. 1995; van Berckel et al. 1996) used in the treatment of schizophrenic patients. 
A

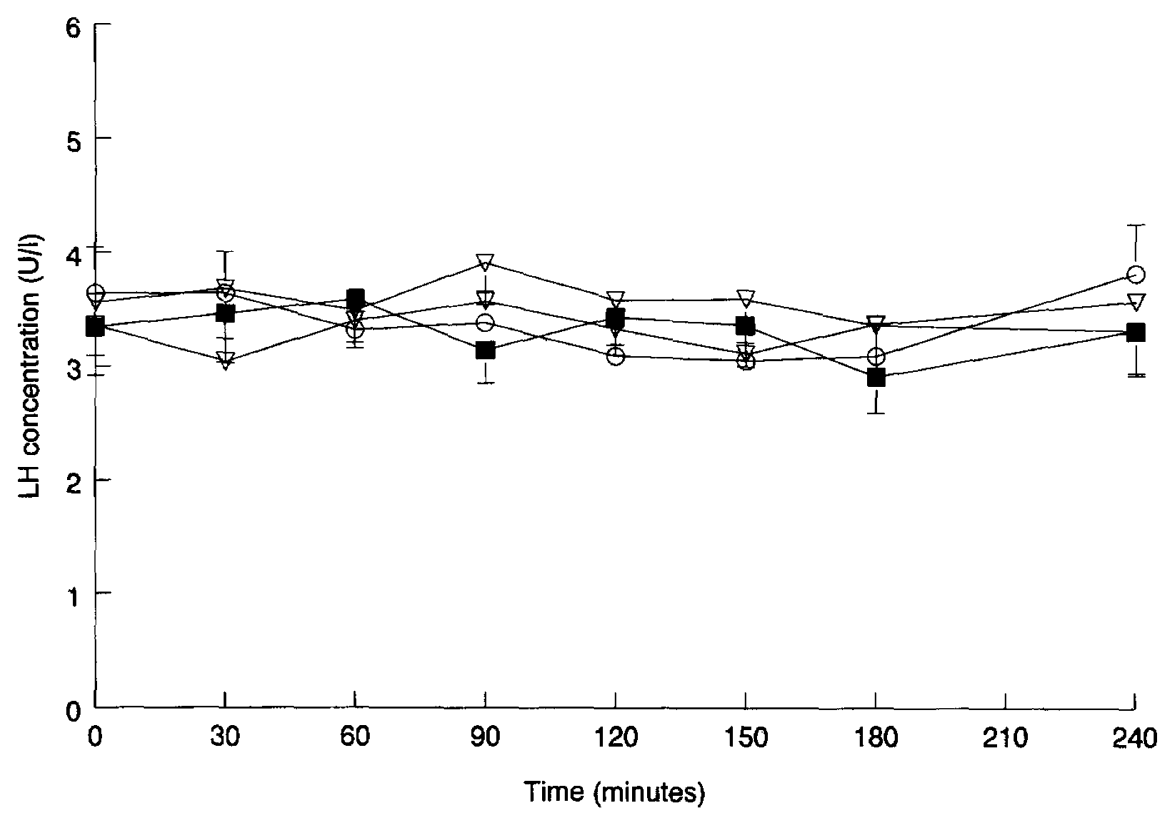

B

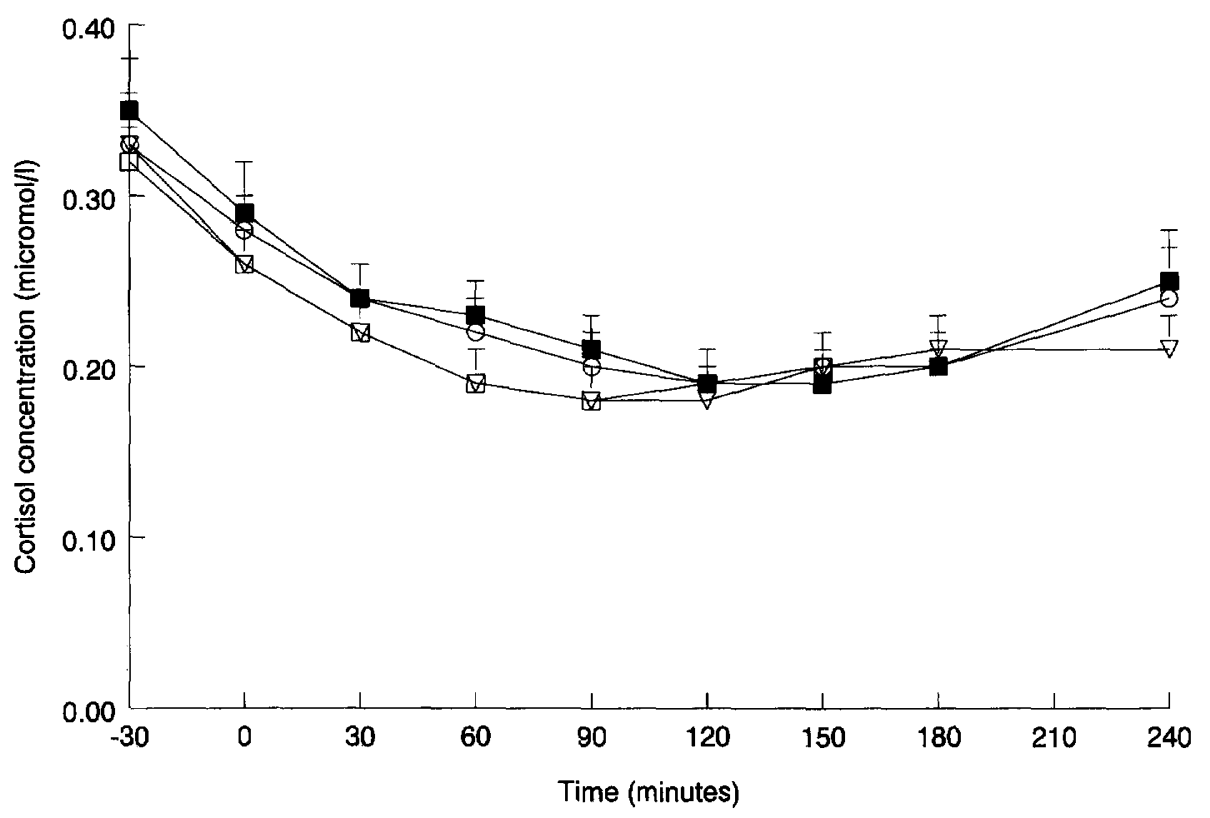

Figure 2. Plasma levels of $\mathrm{LH}$ $(A)$, cortisol $(B)$, and prolactin $(C)$ following oral administration of placebo (solid squares) and $15 \mathrm{mg}$ (circles), $50 \mathrm{mg}$ (triangles), and 150 mg (open squares) D-cycloserine. Each point represents mean \pm SEM obtained from 16 healthy volunteers.
Thus, D-cycloserine in this dose range can readily be administered to human subjects.

A possible explanation for the lack of stimulation of neuroendocrine secretion is the weak efficacy of D-cycloserine as an agonist for the glycine recognition site of the NMDA receptor: D-cycloserine shows only $60 \%$ of the agonistic potency as compared to the endogenous agonist glycine (Chessel et al. 1991). Thus, as a weak, partial agonist of the glycine binding site of the NMDA receptor (Hood et al. 1989; Monahan et al. 1989; Watson et al. 1990; Emmett et al. 1991; Sirvio et al. 1992; Thompson et al. 1992; Pittaluga et al. 1993; Pitkanen et al., 1994), 
C

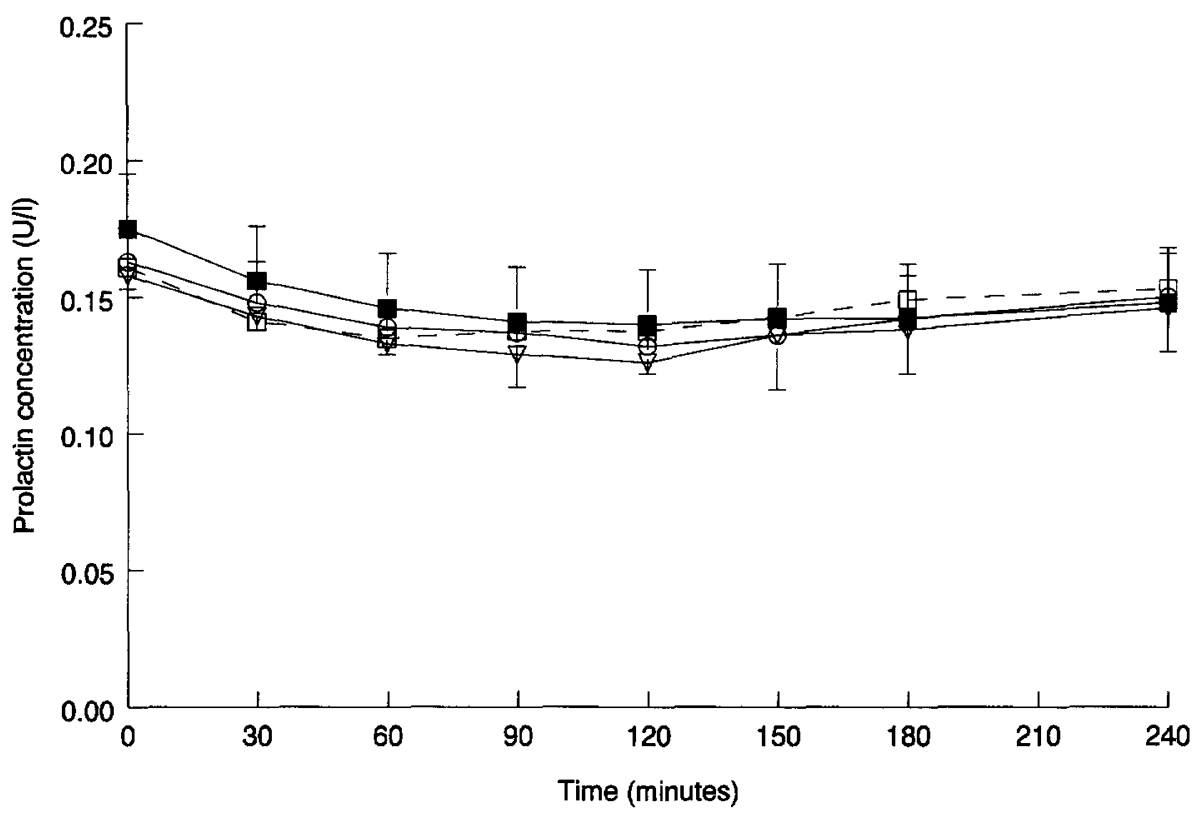

Figure 2. Continued.

the effect of D-cycloserine on the NMDA receptor depends on the occupancy of the glycine binding site by (the endogenous agonist) glycine: if this site is not fully saturated, D-cycloserine in low dosages could enhance the stimulating effects of the endogenous glycine on the NMDA receptor, whereas in higher dosages it is expected to compete with glycine and act as a relative antagonist of this receptor. Indeed, in animals, low dosages of D-cycloserine in a narrow dose range appeared to be able to stimulate the NMDA receptor, as measured in several memory paradigms in animals, indicating that (in animals) endogenous glycine does not fully occupy the glycine recognition site in vivo and that this receptor therefore can be stimulated by low dosages of D-cycloserine (Watson et al. 1990; Chessell et al. 1991; Jones et al. 1991; Flood et al. 1992; Sirvio et al. 1992; Thompson et al. 1992; Pittaluga et al. 1993; Pitkanen et al. 1994). Thus, another explanation for the lack of neuroendocrine effects of low doses of D-cycloserine in healthy subjects might be full occupancy of the glycine recognition site of the human NMDA receptor with endogenous glycine. Furthermore, the highest D-cycloserine dose used in this experiment, $150 \mathrm{mg}$, might have been too low to compete with the endogenous glycine to reveal the expected antagonistic properities of D-cycloserine. Interesting, in patients with schizophrenia D-cycloserine in low doses seems to be able to induce behavioral changes, suggesting that in schizophrenia the glycine recognition site of the NMDA receptor might not be saturated by glycine and, indeed, can be stimulated by D-cycloserine.

In addition, although it has been described that
D-cycloserine readily passes the blood-brain barrier (Hanngren and Hansson 1961), this has been reported only in animals. In humans, only the side effects originating in the central nervous system, like psychosis and epilepsy, after dosages used in the treatment of tuberculosis, that is, $500 \mathrm{mg}$ daily and higher, suggest that D-cycloserine penetrates the blood-barrier in humans (Walker and Murdoch 1957; Vallade 1959). No information is currently available about the bioavailability of D-cycloserine in cerebral fluid in lower dosages. However, the behavioral effects of D-cycloserine in humans indirectly suggest that D-cycloserine in doses of 15 , (Jones et al. 1991), 50 (Goff et al. 1995), and $100 \mathrm{mg}$ (van Berckel et al. 1996) does pass the blood-brain barrier.

Finally, although in animals NMDA receptors are involved in the regulation of secretion of pituitary hormones (Carbone et al. 1996), this might not be the case in humans. Stimulation of neuroendocrine secretion after administration of the NMDA antagonist ketamine (Krystal et al. 1994) is the only indication currently available indicating that indeed NMDA receptors are involved in human neuroendocrine response. However, the interference of ketamine with other receptors might have contributed to this effect. Furthermore, the anxiogenic properties of ketamine could, as described before, also explain the stimulation of cortisol and prolactin secretion. Thus, the role of NMDA receptors in human neuroendocrine secretion still needs to be established.

The present results indicate that D-cycloserine can readily be administered to healthy volunteers but that, in the dosages used in this experiment, D-cycloserine 
failed to elicit a neuroendocrine response. Limited penetration through the blood-brain barrier, weak efficacy of D-cycloserine, and a narrow dose range in which D-cycloserine can stimulate NMDA receptors could explain the lack of neuroendocrine response. Further investigations are needed to assess whether $D$-cycloserine in other dosages can be used as a probe for NMDA receptor function in humans.

\section{ACKNOWLEDGMENTS}

The authors thank C. Braams, A. Klompmakers, and S. de Graaf for their valuable technical assistance; A. F. A. M. Schobben, Pharm. Ph.D., H. G. M. Westenberg, Ph.D., and M. A. Blankenstein, Ph.D., for their critical advice.

\section{REFERENCES}

Andreasen NC (1985): Comprehensive Assessment of Symptoms and History (CASH). Iowa City, University of lowa

Arslan M, Pohl CR, Plant TM (1988): DL-2-amino-5-phosphonopentanoic acid, a specific N-methyl-D-aspartic acid receptor antagonist, suppresses pulsatile $\mathrm{LH}$ release in the rat. Neuroendocrinology 47:465-468

Arslan M, Pohl CR, Smith MS, Plant TM (1992): Studies of the role of the N-methyl-D-aspartate (NMDA) receptor in the hypothalamic control of prolactin secretion. Life Sci 50:295-300

Bond A, Lader M (1974): The use of analogue scales in rating subjective feelings. Br J Med Psychol 47:211-218

Carbone S, Szwarcfarb B, Rondina D, Feleder C, Moguilevsky JA (1996): Differential effects of the N-methyl$\mathrm{D}$-aspartate and non- $\mathrm{N}$-methyl-D-Aspartate receptors of the excitatory amino acids system on LH and FSH secretion. Its effects on the hypothalamic luteinizing hormone releasing hormone during maturation in male rats. Brain Res 707:139-145

Chessell IP, Procter AW, Francis PT, Bowen DM (1991): D-cycloserine, a putative cognitive enhancer, facilitates activation of the N-methyl-D-aspartate receptor-ionophore complex in Alzheimer brain. Brain Res 565:345348

Emmett MR, Mick SJ, Cler JA, Rao TS, Iyengar S, Wood PL (1991): Actions of D-cycloserine at the N-methylD-aspartate-associated glycine receptor site in vivo. Neuropharmacology 30:1167-1171

Endicott J, Spitzer RL (1978): Diagnostic interview: The schedule for affective disorders and schizophrenia. Arch Gen Psychiatry 35:837-844

Flood JF, Morley JE, Lanthorn TH (1992): Effect on memory processing by D-cycloserine, and agonist of the NMDA/ glycine receptor. Eur J Pharmacol 221:249-254

Glazer WM, Charney DS, Heninger GR (1987): Noradrenergic function in schizophrenia. Arch Gen Psychiatry 44:898-904

Goff DC, Tsai GC, Manoach DS, Coyle JT (1995): dose-find- ing trial of D-cycloserine added to neuroleptics for negative symptoms in schizophrenia. Am J Psychiatry 152:1213-1215

Hanngren H, Hansson E, Ullberg S (1961): Antibiotics Chemother 12:45-54

Henn FA (1995): The NMDA receptor as a site for psychopathology-primary or secondary role? Arch Gen Psychiatry 52:1008-1010

Hood WF, Compton RP, Ninahan JB (1989): D-cycloserine: A ligand for the N-methyl-D-aspartate coupled glycine receptor has partial agonist characteristics. Neurosci Lett 98:91-95

Ishimaru M, Kurumaji A, Toru M (1994): Increases in Strychnine-Insensitive Glycine Binding Sites in Cerebral Cortex of Chronic Schizophrenics-Evidence for Glutamate Hypothesis. Biol Psychiatry 35:84-95

Javitt DC, Zukin ST (1991): Recent advances in the phencyclidine model of schizophrenia. Am J Psychiatry 148: 1301-1308

Javitt DC, Zylberman I, Zukin SR, Heresco-Levy U, Lindenmayer J (1994): Amelioration of Negative Symptoms in Schizophremia by Glycine. Am J Psychiatry 151:12341236

Jezova D, Oliver C, Jurcovicova J (1991): Stimulation of adrenocorticotropin but not prolactin and catecholamine release by $\mathrm{N}$-methyl-aspartic acid. Neuroendocrinology 54:488-492

Jones RW, Wesnes KA, Kirby J (1991): Effects of NMDA modulation in scopolamine dementia. Ann N Y Acad Sci 640:241-244

Kahn RS, Wetzler S. (1991): m-Chlorophenylpiperazine as a probe of serotonin function. Biol Psychiatry 30:11391166.

Krystal JH, Karper LP, Seibyl JP, Freeman GK, Delaney R, Bremner JD, Heninger GR, Bowers MB Jr, Charney DS (1994): Subanesthetic effects of the noncompetitive NMDA antagonist, ketamine, in humans. Psychotomimetic, perceptual, cognitive, and neuroendocrine responses. Arch Gen Psychiatry 51:199-214

Lahti AC, Koffel B, Laporte D, Tamminga CA (1995): Subanesthetic doses of ketamine stimulate psychosis in schizophrenia. Neuropsychoparmacology 13:9-19

Luby ED, Gottlieb JS, Cohen BD, Rosenbaum G, Domino EF (1962): Model psychoses and schizophrenia. Am J Psychiatry 119:61-67

Monahan JB, Handelmann GE, Hood WF, Cordi AA (1989): D-cycloserine, a positive modulator of the N-methylD-aspartate receptor, enhances performance of learning tasks in rats. Pharmacol Biochem Behav 34:349-653.

Nishikawa T, Takashima M, Toru M (1983): Increased [3H]kainic acid binding in the prefrontal cortex in schizophrenia. Neurosci Lett 40:245-250

Olney JW, Farber NB (1995): Glutamate receptor by dysfunction and schizophrenia. Arch Gen Psychiatry 52:9981007

Overall JE, and Gorham DR. (1962): The Brief Psychiatric Rating Scale. Psychol Rep 10:799-812

Petersen SL, McCrone S, Keller M, Gardner E. (1991): Rapid increase in LHRH mRNA levels following NMDA. Endocrinology 129:1679-1681 
Pitkanen M, Sirvio J, Lahtinen H, Koivisto E, Riekkinen P. (1994): D-Cycloserine, a Partial Agonist at the Glycine Site, Enhances the Excitability of Dentate Granule Cells in Vivo in Rats. Eur J Pharmacol 253:125-129

Pittaluga A, Fedele E, Risiglione C, Raiteri M (1993): Agerelated decrease of the NMDA receptor-mediated nonadrenaline release in rat hippocampus and partial restoration by D-cycloserine. Eur J Pharmacol 231:129-134

Rivas Salazar IL (1970): On cycloserine in the treatment of pulmonary tuberculosis and its use for postoperative protection. Scand J Respir Dis 71 (Suppl):314-324

Schainker BA, and Cicero TJ (1980): Acute central stimulation of luteinizing hormone by parenterally administered N-methyl-D,L-aspartic acid in the male rat. Brain Res 184:425-437

Sirvio J, Ekonsalo T, Riekkinen PJ, Lahtinen H, Riekkinen PS (1992): D-cycloserine, a modulator of the N-methylD-aspartate receptor, improves spatial learning in rats treated with muscarinic antagonist. Neurosci Lett 146:215-218

Thompson LT, Moskal JR, Disterhoft JF (1992): Hippocampus-dependent learning facilitated by a monoclonal antibody or D-cycloserine. Nature 359:638-641.

Toru M, Watanabe S, Shibuya H, Nishikawa T, Noda K, Mitsushio H, Ichikawa H, Kurumaji A, Takashima M, Mataga N, Ogawa A (1988): Neurotransmitters, receptors and neuropeptides in post-mortem brains of chronic schizophrenic patients. Acta Psychiatr Scand 78:121-137

Tsai G, Passani LA, Slusher BS, Carter R, Baer L, Kleinman JE, Coyle JT (1995): Abnormal Excitatory Neurotransmitter Metabolism in Schizophrenic Brains. Arch Gen Psychiatry 52:829-836

Vallade LH (1959): La Neuro-toxicité de la Cycloserine Mise au point de ses manifestations cliniques et électroencéphalographiques d'après 30 publications françaises. La Presse Medicale 67(4):138-140

van Berckel BNM, Hijman R, van der Linden JA, Westenberg HGM, van Ree JM, Kahn RS (1996): Efficacy and Tolerance of D-cycloserine in drug-free schizophrenic patients. Biol Psychiatry 40(12):1298-1300

van den Brink W, De Jong CAJ (1992): Nederlandse vertaling van de Structured Interview for DSM-III-R Personality: SIDP-R. IVB-Reeks 2

van den Pol AN, Wuarin JP, Dudek FE (1990): Glutamate, the dominant excitatory transmitter in neuroendocrine regulation. Science 250:1276-1278

Walker WC, Murdoch JM. (1957): Cycloserine in the Treatment of Pulmonary Tuberculosis. A Report on Toxicity. Tubercle (Lond) 38:297

Watson GB, Bolanowski MA, Baganoff MP, Deppeler CL, Lanthorn TH (1990): D-cycloserine acts as a partial agonist at the glycine modulatory site of the NMDA receptor expressed in Xenopus oocytes. Brain Res, 510:158-160 